\title{
Online Based Memorandum of Understanding (MOU) Data Exchange System Design with EDI Method
}

\author{
Inge Virdyna Samidi* \\ Department of Computer Science, Budi Luhur University, Indonesia
}

\begin{abstract}
During the Covid 19 pandemic, every individual is required to be more creative in carrying out every activity and not make a distance as the reason an activity cannot be carried out. Documentation data, which is usually sent manually by post, will experience difficulties at this time. This research will discuss other ways that can be done to ensure the data exchange process of the Memorandum of Understanding (MOU) between PT. Bank XYZ with partners. The solution that can be implemented is to use the Electronic Data Interchange (EDI) method. EDI is an online-based data exchange method. In other words, the method of exchanging data via postal service is not necessary. Based on this research, the EDI method can meet users' needs in terms of exchanging or sending documentary data on the MOU between PT. Bank $X Y Z$ with partners. The method used in building this system design is analyzing the running system and designing the system with UML tools. The final result of the validation test of the system design through the FGD method states that the $e$ approval system application design of the MOU is by the specifications of the functional requirements required by the user.
\end{abstract}

This is an open access article under the CC BY-SA license

\author{
Keywords: \\ EDI; \\ $F G D$; \\ Prototype; \\ MOU;
}

Article History:

Received: July 5, 2021

Revised: November 6, 2021

Accepted: November 10, 2021

Published: November 25, 2021

Corresponding Author:

Samidi

Department of Computer Science, Budi Luhur University, Indonesia

Email: samidi@budiluhur.ac.id

\section{INTRODUCTION}

A Memorandum of Understanding (MOU) is a legal bond that connects two or more parties where each party binds itself to do the agreed upon. The use of technology in processing an MOU is able to provide information in the form of accuracy in information about the course of a cooperation process. In addition, the security of the data from this process is guaranteed. Therefore, the process of MOU negotiations, data storage of MOU, and reports on the MOU process can be more effective if done with computers $[1,2]$.

PT. Bank XYZ already has an application that can meet users' needs in supervising every process of making an MOU until the report that will be presented. However, the previous information system design for the PT. Bank XYZ used to exchange documentation data from partners to PT. Bank XYZ is still inaccurate, so existing applications can be ascertained that it is not optimal. Furthermore, the exchange of MOU documents still uses postal exchange services. The condition can result in insecure data security during the exchange process [3, 4].

The problem formulation of this research is how to create an information system for the process of exchanging data on MOU documentation that is accurate, efficient, effective, and able to guarantee the security of available data as needed at PT. Bank XYZ and partners using the EDI method. Then, the problem formulation of this research is whether the information system process of exchanging data on MOU documentation using the prototype development method is the right way to solve the identified problem.

The presence of the Electronic Data Interchange (EDI) method can be a solution for making business transactions efficient on the internet and at the same time providing security guarantees 
in transactions $[5,6,7,8,9,10]$. The purpose of this research was to create a model analysis and software implementation for the development of information systems for the MOU process at PT. Bank XYZ, which is centered on the process of exchanging documentation data so that its management is more accurate, structured, and efficient with the EDI method.

\section{MATERIAL AND METHOD \\ FGD}

Focus Group Discussion (FGD) is a systematic process of collecting data and information on a specific problem through group discussions. The FGD focused more on discussions, not interviews. There is a difference between the FGD and the interview technique. The FGD presents a problem, a case, and an incident as material for discussion [11, 12].

Methodologically, the FGD was conducted because there was a belief that the problem under study could not be understood by the survey method or individual interviews. After all, group opinion was very important. In addition, this method makes it easy to obtain quality qualitative data in a relatively short time $[13,14]$.

\section{Electronic Data Interchange (EDI)}

Electronic Data Interchange (EDI) is a structured data transfer process in an approved standard format from one computer system to another in electronic form. For example, an MOU has a significant effect on running an MOU between a company and its partners. This term is generally used in the context of commerce and business, especially electronic commerce or ecommerce. Usually, used by companies in facilitating the process of exchanging repeated transaction data between companies [7].

The purpose of implementing EDI is to help business people process a document with other parties accurately, quickly, and efficiently in its completion. If the process is carried out as well as possible, there will be excellent communication among fellow business actors, both internally and externally $[9,10]$.

\section{Unified Modelling Language (UML)}

Unified Modelling Language (UML) is a language used to define, visualize, build, and document an information system $[15,16]$. UML was developed for object-oriented analysis and design by Grady Booch, Jim Rumbaugh, and Ivar Jacobson [17].

However, UML can be used to understand and document any information system. The use of UML in the industry continues to increase. It is an open standard which makes it a common modeling language in the software industry and systems development [17].

UML provides ten kinds of diagrams for object-oriented modeling applications, as follows:

1. Use Case Diagram to model business processes.

2. Conceptual Diagram to model the concepts that exist in the application.

3. Sequence Diagram to model message exchange between objects.

4. Collaboration Diagram to model interactions between objects.

5. State Diagram to model object behavior in the system.

6. Activity Diagram to model the behavior of Use Cases and objects in the system.

7. Class Diagram to model the class structure.

8. Object Diagram to model the structure of the object.

9. Component Diagram to model the component object.

10. Deployment Diagram to model application distribution.

This research will focus on four types of diagrams. There are use case diagrams, sequence diagrams, activity diagrams, and class diagrams. 


\section{Entity Relationship Diagram}

Designing a database program describes modeling from the real world into an entity-relation model (E-R Model), better known as an Entity Relational Diagram (ERD) [18, 19, 20]. ERD is an expression of the actual state into a collection of basic objects called entities through relationships between these entities. In ERD or data modeling, there are three components: Data Entity, Data Attributes, and Data Relationship. In Data Entity, the entity is anything for which data is collected. For example, entities can be objects, people, abstract concepts, or events. In Data Attributes, the Attributes are those of an entity. Finally, in Data Relationship, the relationship is a relation between an entity and another entity. For example, cardinality Data Relationship consists of One to One Relationship of Two File, One to Many Relationships of Two File, and Many to Many Relationships File. These relationships are depicted in Figure 1, Figure 2 and Figure 3.

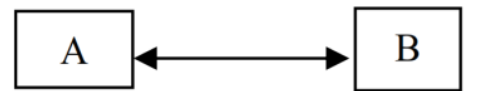

Figure 1. One to One Relationship

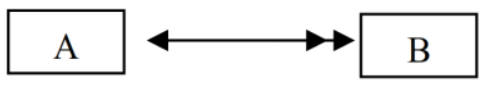

Figure 2. One to Many Relationship

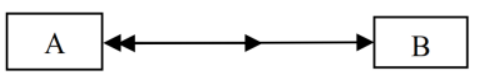

Figure 3. Many to Many Relationship

\section{Memorandum of Understanding (MOU)}

An MOU is a mutual agreement made by two parties on some issues to achieve common goals. The Civil Code does not recognize the term MOU as a form of pouring out the parties' arrangement. However, according to Sunu Widi Purwoko, the form is used from time to time as a habit of pouring out the commitment of the parties to do something in the future [5].

Binder verbs that are widely used in agreements such as "obliged" or "must" in the MOU are replaced by the word "will". If one party neglects its commitment, the other party cannot sue because the commitment referred to is a "promise to do something". So, from the start, MOU entrants must be aware that the commitment of each new party is limited to "promise to do something" not "obligation to do something" [5].

\section{Method}

The object of research is the Information System for the MOU Process of PT. Bank XYZ, located in Central Jakarta, DKI Jakarta. In carrying out its business activities, Bank XYZ has obtained a business license in the field of Life Insurance. The establishment of Bank XYZ is in line with the needs of its parent company, one of the national banks in Indonesia, to provide integrated financial services and services for all its customers (one-stop financial services). The Company's vision is to become the leading insurance company that is the pride of the nation. Company Mission Providing reliable future planning and protection solutions with excellent service to stakeholders with all its conveniences through continuous innovation.

This research category is descriptive research in which stages are carried out by analyzing stakeholders' system requirements, then making a system design with UML tools and testing the validation of the system design with FGD. Observations are made to retrieve and collect data directly from the field, classify the data, analyze and process the data to support the data obtained.

\section{RESULTS AND DISCUSSION System Analysis}

Based on the discussion that has been presented in previous chapters, this research focuses on the flow of data exchange based on online MOU documentation. Therefore, the Electronic 
Data Interchange (EDI) method is suitable for meeting the needs of an online-based MOU documentation data exchange system. Figure 4 shows an overview of the proposed system.

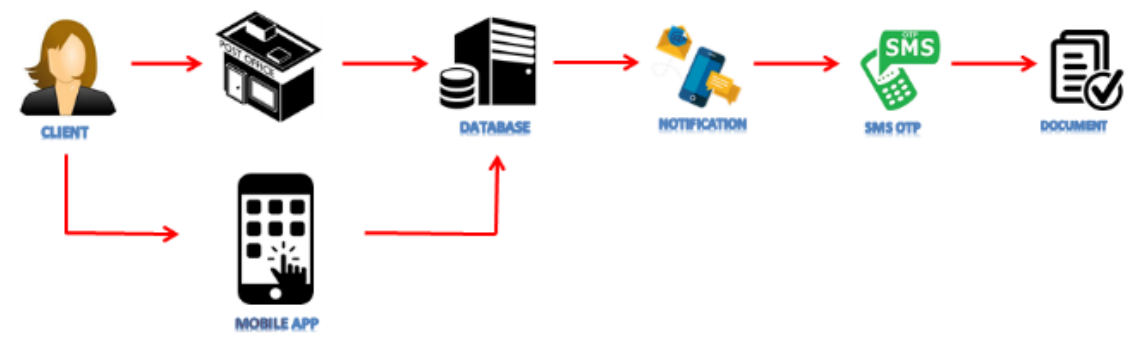

Figure 4. Proposed of The System Flow

The previous documentation data exchange used manual postal exchange services. The system development is carried out by exchanging data online using a mobile application integrated with the existing MOU system. The partners will be directed to have a mobile application that functions to exchange data. Then the entire negotiation process regarding the contents of the MOU will be carried out online until an agreement between the two parties is reached.

\section{System Design}

In this section, modeling is carried out using the Unified Modeling Language (UML). The design of the data exchange system for the documentation of the MOU can be seen based on the use case diagram, sequence diagram, activity diagram, and class diagram, as follows:

\section{Use Case Diagram}

Figure 5 shows the role of the user and how that role is when using the system. Use case diagrams can also be used to represent user interactions with the system and describe use case specifications.

\section{Sequence Diagram}

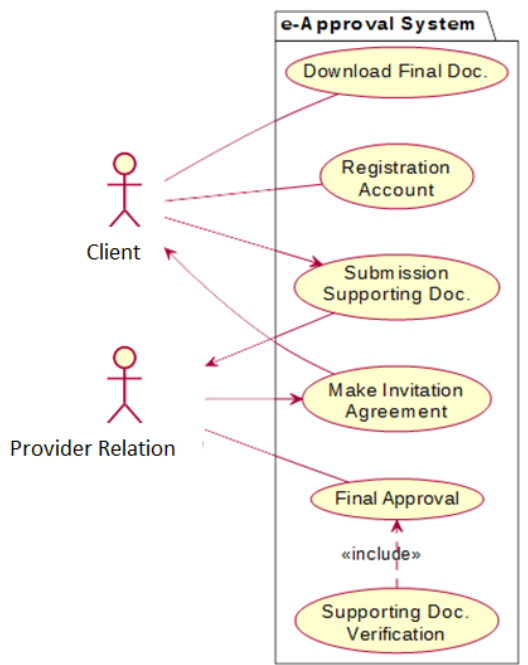

Figure 5. Use Case Diagram

Sequence diagrams are diagrams depicting user interactions with the system sequentially (sequentially). The sequence diagrams made by the author focused on two activities: registration accounts and downloading final documents. Figure 6 and Figure 7 show the sequence diagrams. 
In this activity, partners are required to register for an account to initiate data exchange activities on online-based MOU documentation. The partner responsible for working on the MOU process will download the application and complete the data needed for the authentication process on the mobile application.

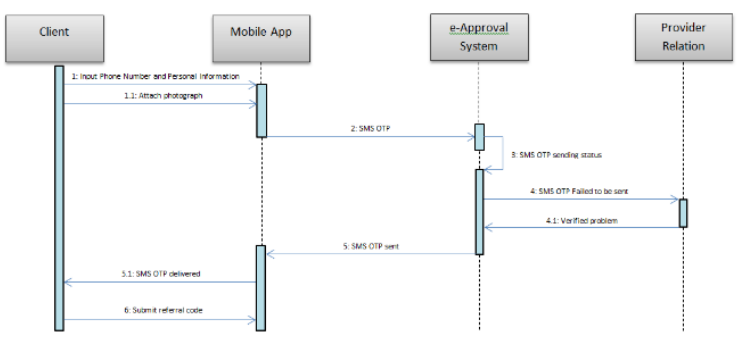

Figure 6. Registration Account

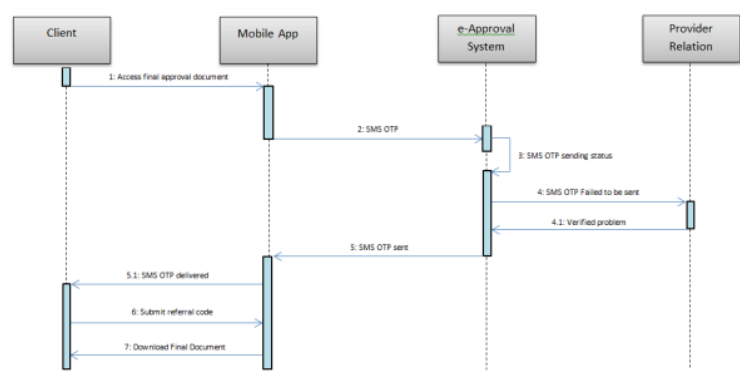

Figure 7. Download Final Document

In addition to account registration, the download activity of the MOU document has been agreed upon by the partner. The PT. Bank XYZ is also the focus of researchers to describe it in the form of a sequence diagram. In this process, partners are required to follow an authentication process that also uses the SMS OTP function to verify the validity of user data before downloading the MOU document.

\section{Activity Diagram}

Activity diagrams describe the workflow of various user or system activities, individuals who carry out activities, and the sequential flow of these activities. Based on the use case diagram that has been designed, the MOU documentation data exchange system has 12 detailed activities.

a. The activity of Cooperation Submission

The initial activity carried out is that the partner makes a submission letter to enter into an MOU. The situation, as shown in Figure 8, is usually done by manually sending email notifications. When PT. Bank XYZ agrees and is interested in entering into an MOU, the Provider Relation division will make an approval invitation that will be sent via SMS.

b. The activity of Agreement Assignment Invitation

The e-approval system will process the sending of the invitation link to the partner, as depicted in Figure 9.

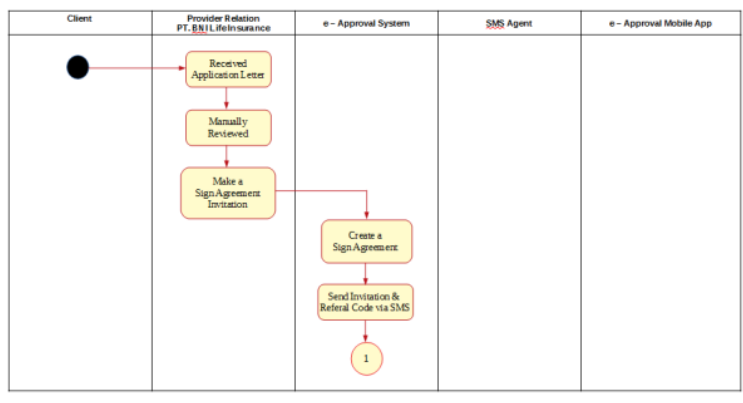

Figure 8. Activity Agreement Assignment

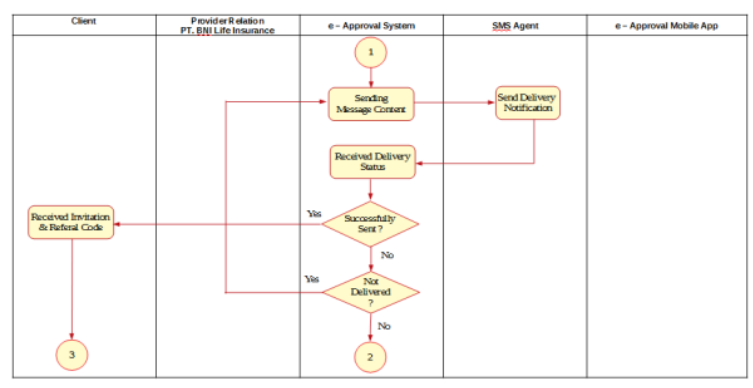

Figure 9. Activity of the Sending of Agreement Assignment 
c. The activity of Account Creation

The invitation link will direct the partner to create an account on the mobile application. Then, the e-approval system will carry out the authentication process as shown in Figure 10.

d. The activity of the Account Registration Process

In this process, the e-approval system authenticates by sending a verification code to the partner's cellphone. Figure 11 shows the activity of account registration process.

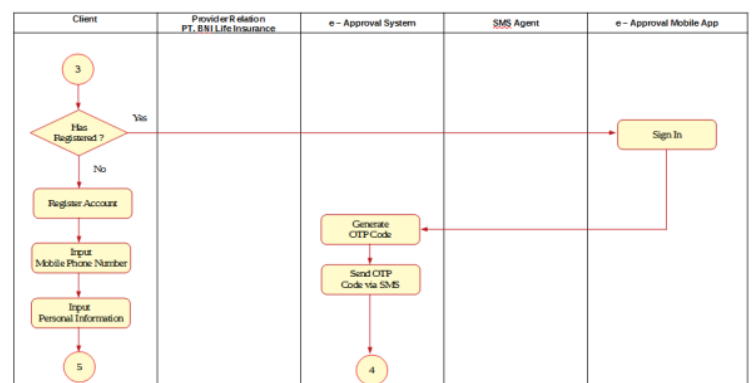

Figure 10. Activity of Account Creation

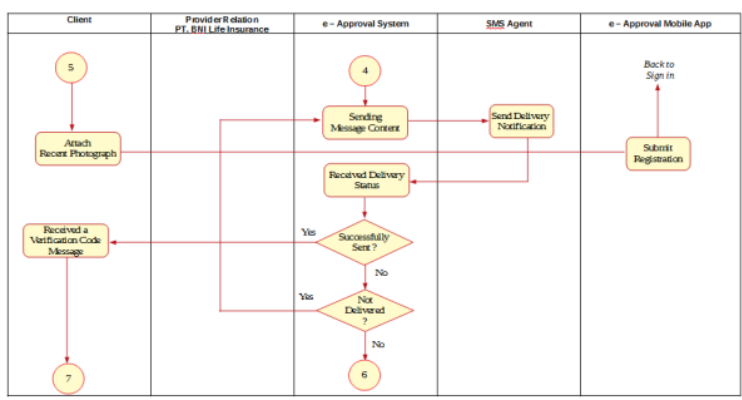

Figure 11. Activity of Account Registration Process

e. The activity of Error Handling in the Authentication Process

When Provider Relation gets a notification that an authentication SMS has not been sent, the Provider Relation will handle it by reporting the problem to the administrator. Activity of error handling in the authentication process is shown in Figure 12.

f. The activity of Authentication and Validation Process

In this process, the system will send a verification code and process whether the user inputted code is valid. Figure 13 shows the activity of authentication and validation process.

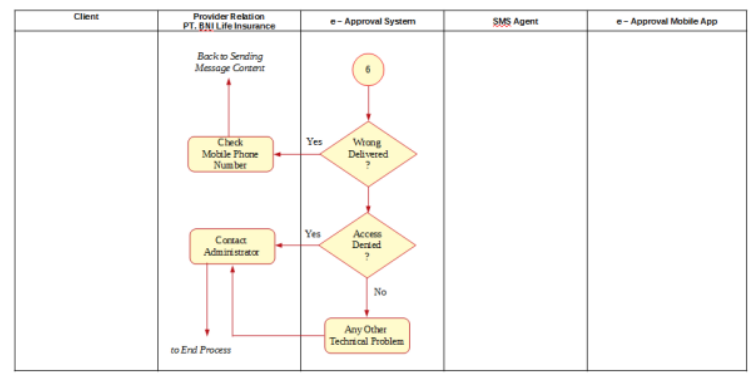

Figure 12. Activity of Error Handling in the Authentication Process

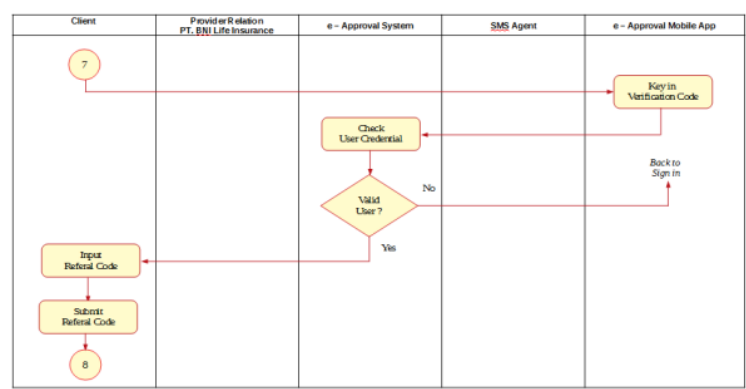

Figure 13. Activity of Authentication and Validation Process

g. The activity of The Process of Uploading MOU Documentation

This process, as depicted in Figure 14, asks partners to validate individual data and upload the final documentation that has been agreed upon from the partner's side.

h. The activity of the MOU Documentation Verification Process

In this process, Provider Relation will validate personal data and verify the MOU documents that have been uploaded by partners online. The proses is illustrated in Figure 15. 


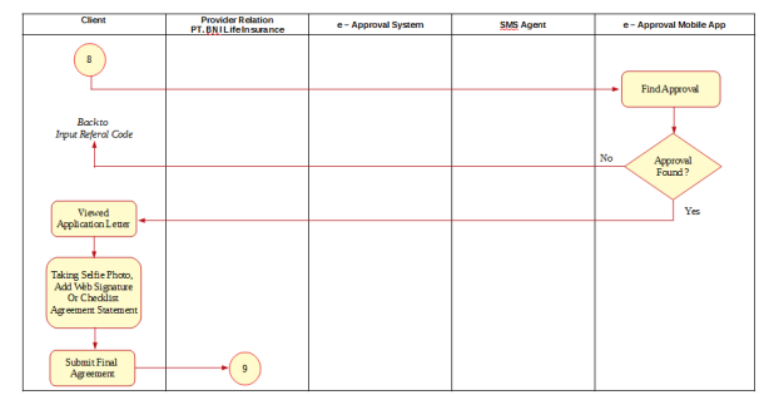

Figure 14. Activity of The Process of Uploading MOU Documentation

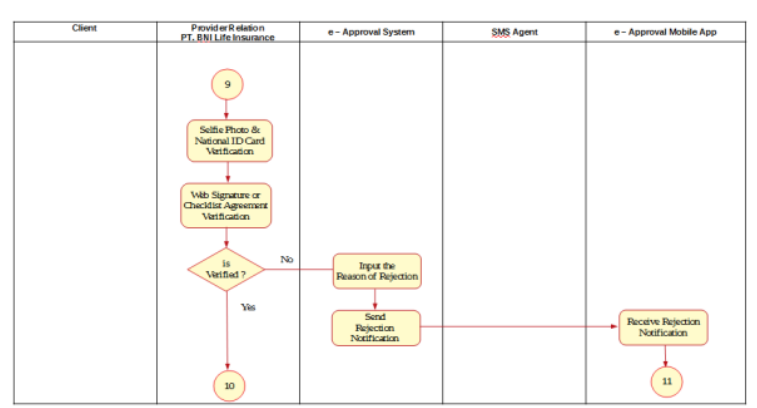

Figure 15. Activity of MOU Documentation Verification Process

i. The activity of MOU Ratification

The next process, as shown in Figure 16, if the documentation passes the validation and verification process, and PT. Bank XYZ approves the MOU contents. The MOU will be sent to the partner online.

j. The activity of Verification Process with OTP Code

Before the partner downloads the MOU data, the system will ask the partner to verify via SMS OTP. Activity of verification process with OTP code shown in Figure 17.

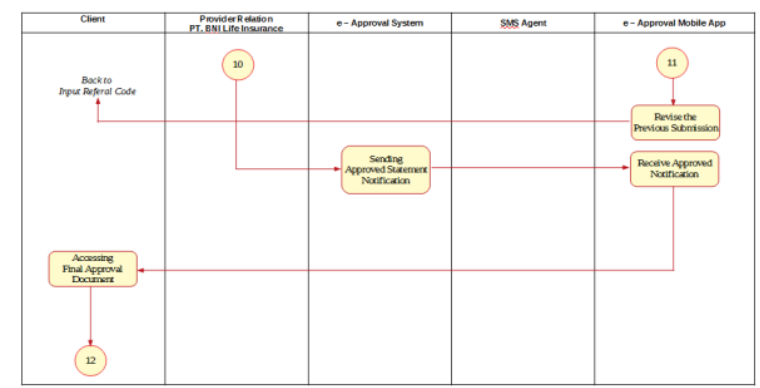

Figure 16. Activity of MOU Ratification

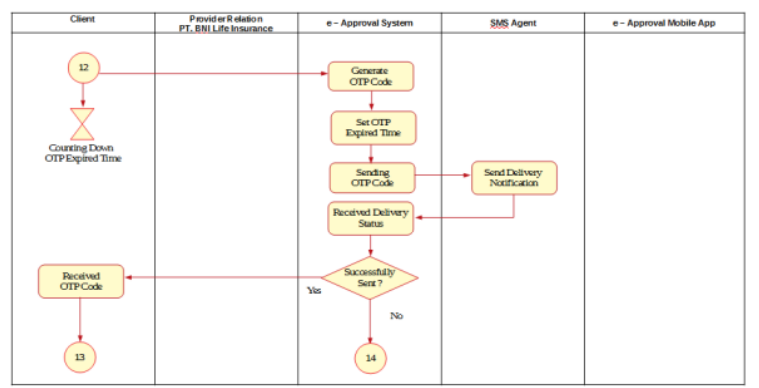

Figure 17. Activity of Verification Process with OTP Code

k. The activity of Expired OTP Code Handling

If the OTP code expires, the system will resend the code. If the OTP SMS is not sent successfully, the system will do troubleshooting. The activity is shown in Figure 18.

1. The activity of the MOU Download Process

If the OTP code is appropriate, the partner can download the data of the MOU that has been agreed upon by both parties. Figure 19 shows the activity.

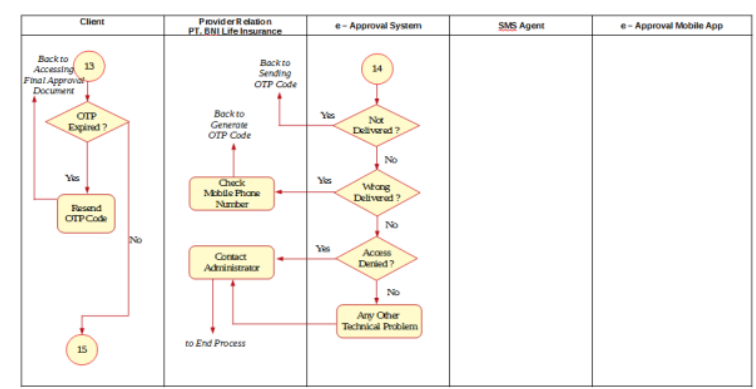

Figure 18. Activity of Expired OTP Code Handling

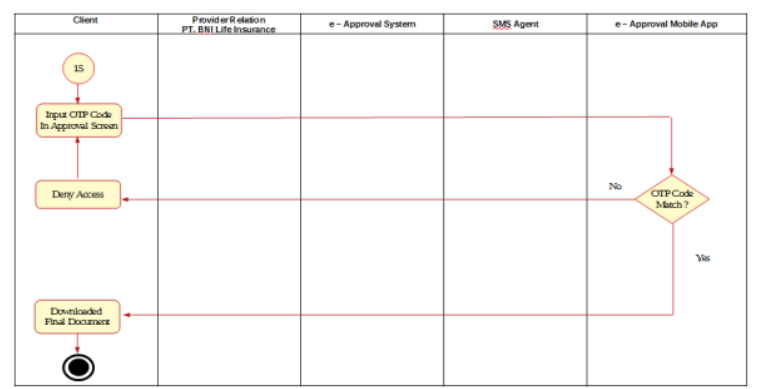

Figure 19. Activity of Expired OTP Code Handling 


\section{Class Diagram}

The class diagram is a diagram that describes the relationship between classes in a system that is being created. The relationships between the classes in this system is shown in Figure 20.

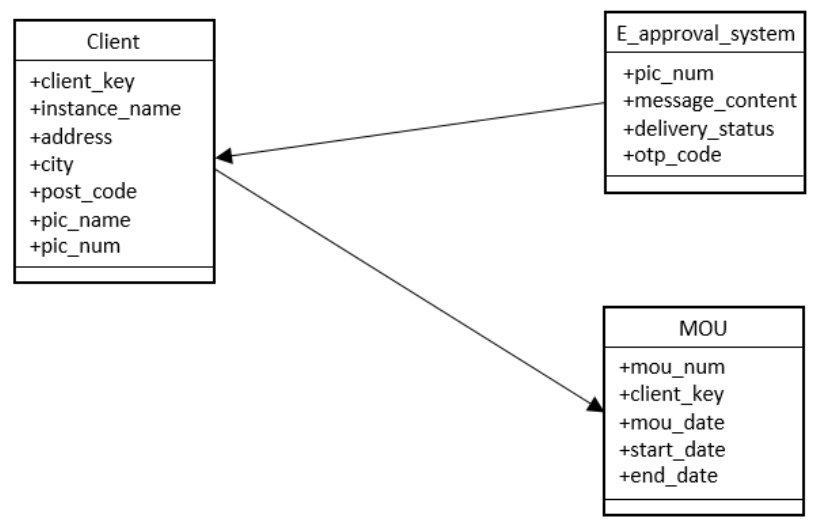

Figure 20. Class Diagram

\section{Database Design}

Database design in this research will be presented in the form of ERD (Entity Relationship Diagram). ERD is a diagram that describes the relationship between each entity in a system. For example, the relationship of each entity in the data exchange system documentation of the MOU between the partner and PT. Bank XYZ is depicted in Figure 21.

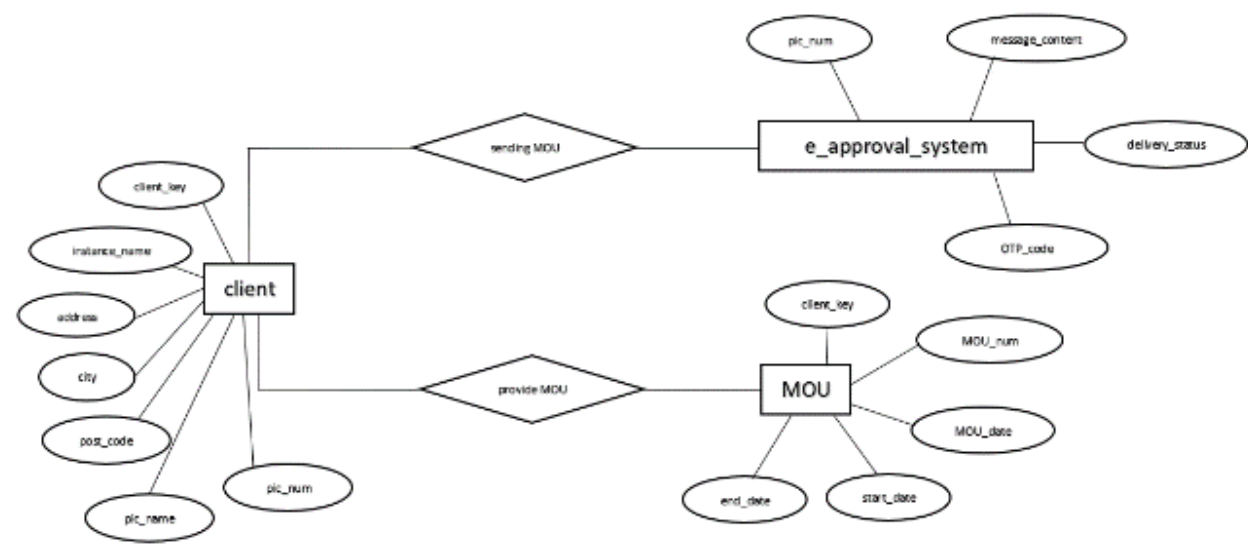

Figure 21. Database Design

\section{User Interface Design}

Interface design in this research shows the design of an android application that partners will use. There are pages designed for User Interface, such as Opening Page, Account Registration Page, SMS OTP Page, Data Uploading Page and Data Downloading Page. Opening Page is the opening page that provides partners with a choice of two buttons that will refer to the application access page or registration for a new account in the application. Account Registration Page is the account registration page that contains parameters that are used as input values for data from application users, in this case, the PIC of the partner who will use the application. Finally, SMS OTP Page appears on several system functions, which are during application registration / accessing, data uploading, and data downloading. Opening Page, Account Registration Page, and SMS OTP Page are shown in Figure 22, Figure 23 and Figure 24, respectively. 


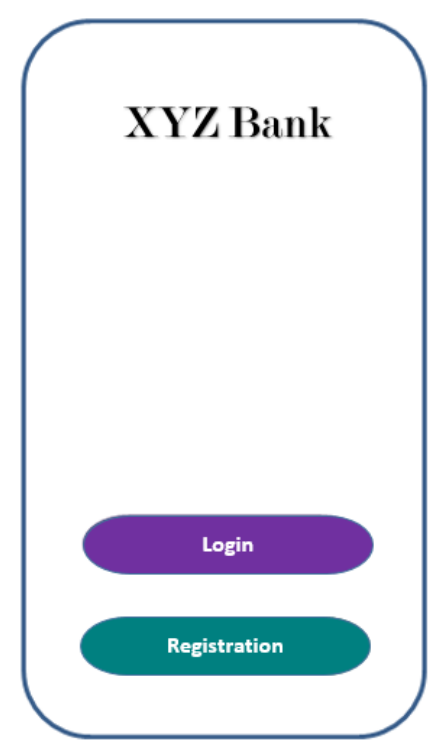

Figure 22. Opening Page

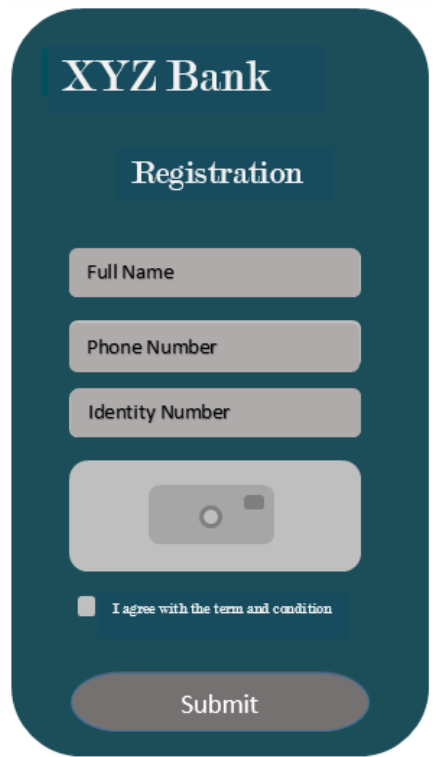

Figure 23. Account Registration Page

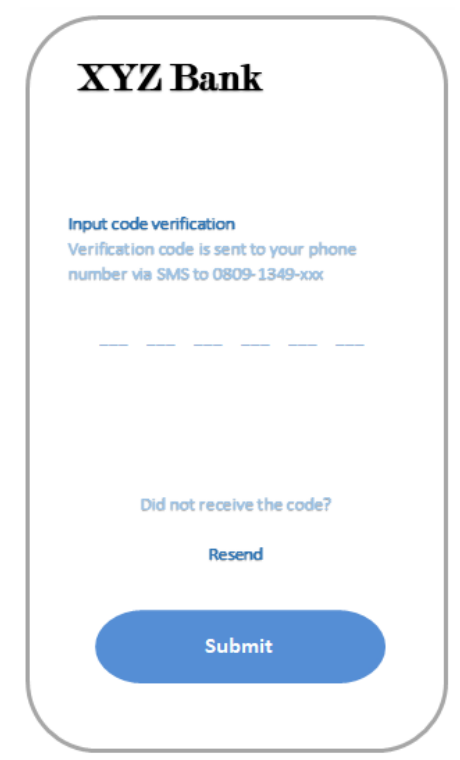

Figure 24. SMS OTP Page

On the other side, Data Uploading Page is the page for partners to be directed to the data upload page to upload data of the MO documentation. On this page, partners are allowed to upload several data at once. Finally, Data Downloading Page is the page that after both parties agree on the contents of the MOU, the partner can download the MOU data. Figure 25 and Figure 26 show the Data Uploading Page and Data Downloading Page.

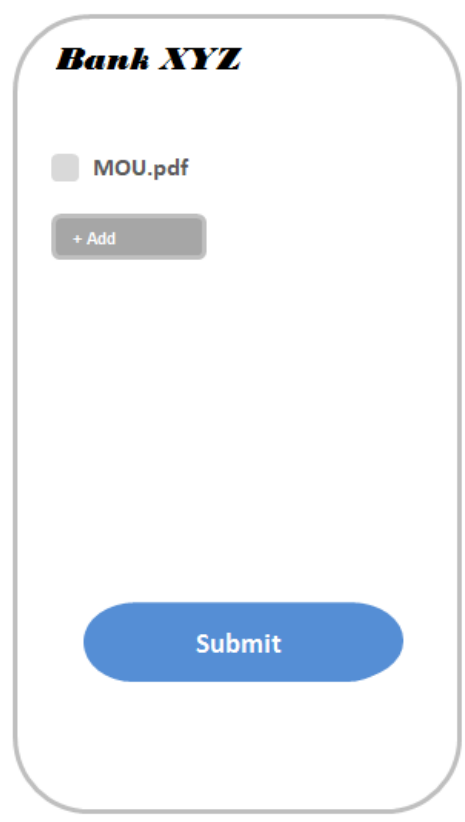

Figure 25. Data Uploading Page

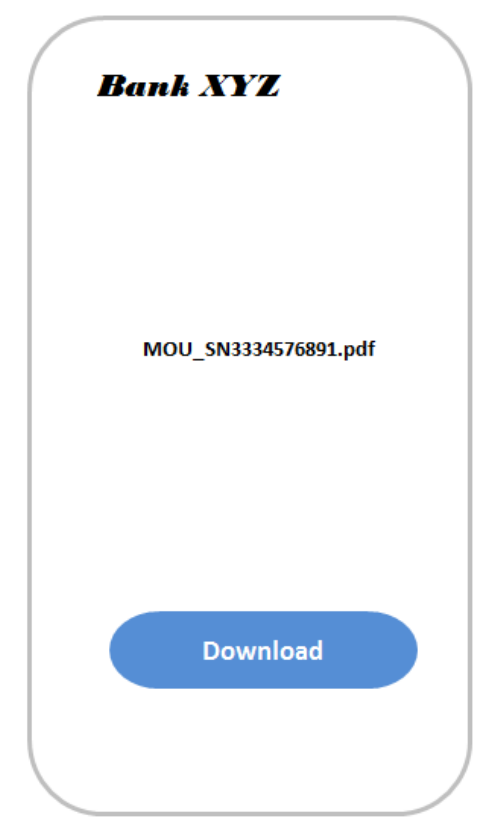

Figure 26. Data Downloading Page

\section{Validation Testing of System Design}

Based on the Focus Group Discussion, the test results can then be recapitulated based on the types of users of the respondents in the FGD. 


\section{Results of Validation Testing of Functional Requirements Specifications}

There are two types of validation testing: types of partner users and types of Provider Relation of department users. Three informants carried out the validation test for the kind of partner user with the code MS (served as the partner legal Staff), JM (served as the partner GA Manager), and LD (served as the partner Marketing Staff Staff). The entire test result is listed in Table 1. The validation test for the type of user in the Provider Relation division was carried out by two informants with the code SY (serving as Provider Relation staff) and DS (serving as head of the Provider Relation section). Table 2 shows the result.

Table 1. Results of Validation Testing Types of Partner Users

\begin{tabular}{|c|c|c|c|c|c|}
\hline \multirow[t]{2}{*}{ \# } & \multirow[t]{2}{*}{ Functional Need Specification } & \multirow[t]{2}{*}{ Subsystem / Module } & \multicolumn{2}{|c|}{$\begin{array}{c}\text { Respondent's } \\
\text { Response }\end{array}$} & \multirow[t]{2}{*}{ Conclusion } \\
\hline & & & Accepted & Denied & \\
\hline 1 & E-Approval account registration & User & 3 & & Agreed \\
\hline 2 & E-Approval login account & User & 3 & & Agreed \\
\hline 3 & User account management & User & 3 & & Agreed \\
\hline 4 & SMS OTP exchange & Account data verification & 3 & & Agreed \\
\hline 5 & OTP code verification & User data verification & 3 & & Agreed \\
\hline 6 & SMS notification & Notification & 3 & & Agreed \\
\hline 7 & Email notification & Notification & 3 & & Agreed \\
\hline 8 & MOU documentation management & MOU data & 3 & & Agreed \\
\hline 9 & E-Approval login account & User & 3 & & Agreed \\
\hline
\end{tabular}

Table 2. Result of Validation Testing Types of Provider Relation Department

\begin{tabular}{|c|c|c|c|c|c|}
\hline \multirow[t]{2}{*}{ \# } & \multirow{2}{*}{ Functional Need Specification } & \multirow{2}{*}{ Subsystem / Module } & \multicolumn{2}{|c|}{$\begin{array}{l}\text { Respondent's } \\
\text { Response }\end{array}$} & \multirow{2}{*}{ Conclusion } \\
\hline & & & Accepted & Denied & \\
\hline 1 & Partner data management & Partner data & 2 & & Agreed \\
\hline 2 & User account management & User & 2 & & Agreed \\
\hline 3 & MOU documentation management & MOU data & 2 & & Agreed \\
\hline 4 & Notification data management & Notification data & 2 & & Agreed \\
\hline
\end{tabular}

Based on the results listed in Table 1 and Table 2, overall, the respondents stated that the eapproval application for this MOU function was accepted and agreed to the results of the tests carried out.

\section{Result of Validation Testing for The Overall Function of the System}

Responses to the function of an electronic-based data exchange system that can provide eapproval of MOUs that are integrated with existing systems, and can increase the speed of information service data exchange documentation of MOUs which is also very good. Following are the responses from the respondents. The design of an electronic-based e-approval MOU data exchange system application can function to provide integrated MOU data. The resulted data is listed in Table 3. Based on Table 3 regarding the answers to the informants from the FGD results above, it can be seen that the informants' responses agree that the e-approval application function of the memorandum of agreement can function to facilitate the data exchange process and integrate it with existing MOU data processing applications. Furthermore, on average, the informants mentioned the speed of the data exchange process.

The data of e-approval based data exchange system application can function to provide information services for the MOU process is listed in Table 4. Based on Table 4, regarding the answers to the informants from the FGD results above, it can be seen that the responses of the informants agree that the e-approval system application function of the memorandum of 
agreement can accelerate the data exchange service of the memorandum of agreement documentation. The informant said that the speed in data exchange could accelerate managing the memorandum of agreement data.

Table 3. Respondent's Responses to System Functions Can Provide Integrated MOU Data

\begin{tabular}{ccclc}
\hline$\#$ & Code & User & \multicolumn{1}{c}{ Response } & Conclusion \\
\hline 1 & MS & Staff & $\begin{array}{l}\text { It is really helpful for completing tasks because } \\
\text { the system speed is faster } \\
\text { It helps the data exchange process because we do } \\
\text { not need to go to the post office } \\
\text { This system makes it easier for us process of } \\
\text { exchanging MoU documents with our partners } \\
\text { We do not have to wait for the delivery of } \\
\text { documentation in a few days } \\
\text { This system is very helpful and simplifies the } \\
\text { process of exchanging the MOU documentation } \\
\text { data }\end{array}$ & Aanager \\
\hline
\end{tabular}

Table 4. Respondents' Responses to System Functions in Increasing Information Service Speed for the MOU

\begin{tabular}{|c|c|c|c|c|}
\hline \multicolumn{5}{|c|}{ Process } \\
\hline \# & Code & User & Response & Conclusion \\
\hline 1 & MS & Staff & $\begin{array}{l}\text { It helps speed up the process of exchanging } \mathrm{MoU} \\
\text { data }\end{array}$ & Agreed \\
\hline 2 & $\mathrm{JM}$ & Manager & $\begin{array}{l}\text { This information system makes it easier and faster } \\
\text { for the services provided }\end{array}$ & Agreed \\
\hline 3 & LD & Staff & $\begin{array}{l}\text { Facilitate the process of exchanging MoU } \\
\text { documentation data to be faster and more efficient }\end{array}$ & Agreed \\
\hline 4 & SY & Staff & $\begin{array}{l}\text { Facilitate the data exchange process without } \\
\text { having to come off the post office manually }\end{array}$ & Agreed \\
\hline 5 & DS & $\begin{array}{l}\text { Team } \\
\text { Leader }\end{array}$ & Greatly speed up the data exchange process & Agreed \\
\hline
\end{tabular}

Based on the results of the FGD, it can be concluded that the e-approval system application design of the memorandum of agreement is by the functional requirements specifications required by the user. Thus, based on the results of analysis, design, and software development for the e-approval system for the memorandum of agreement at PT. Jiwasraya Insurance, based on the mobile app with the EDI method, can provide data exchange of memorandum of agreement documentation with good service speed.

\section{CONCLUSION}

Based on the discussion in the previous chapters and answering the problem formulation, research objectives and referring to the process and results of data analysis in this study, it can be concluded that the information system process of exchanging data on a memorandum of agreement documentation becomes more accurate, efficient, effective, and able to ensure the security of the data available in accordance with the needs of PT. Bank XYZ and partners with the application of the EDI method. Furthermore, based on the validation test results on the eapproval system application design, the memorandum of agreement is in accordance with the specifications of the functional requirements required by the user.

\section{REFERRENCE}

[1] E. Deliana, "Memorandum of Understanding in the Context of Indonesian International Treaty, Advances in Social Science," Education and Humanities Research, vol. 442, pp. 122-124, 2020 
[2] O. V. Putra, Y. Suryadarma, Y. Yoke, and M. A. Maulana, "Design of Management Information Systems Memorandum of Understanding (MoU) And Memorandum of Agreement (MoA) Universitas Darussalam Gontor," Applied Technology and Computing Science Journal, vol. 4, no. 1, pp. 16-25, 2021, doi: 10.33086/ atcsj.v4i1.2152

[3] NN, "Belgium: Technical Note on Crisis Management and Bank Resolution Framework," International Monetary Fund, vol. 2013, no. 135, pp. 37-46, 2013, doi: 10.5089/9781484349663.002

[4] J. Clifton, D. Diaz-Fuentes and D. Howarth, Regional Development Banks in the World Economy, Oxford University Press, UK. 2021

[5] B. E. Blakely, P. Pawar, L. Jololian and S. Prabhaker, "The Convergence of EDI, Blockchain, and Big Data in Health Care," SoutheastCon 2021, Atlanta, GA, US, 2021, pp. 1-5, doi: 10.1109/SoutheastCon45413.2021.9401897.

[6] V. Klapitaa, "Implementation of Electronic Data Interchange as a Method of Communication Between Customers and Transport Company," Transportation Research Procedia, vol. 53, pp. 174-179, 2021, doi: 10.1016/j.trpro.2021.02.023

[7] M. Gian and S. Ikate, "Development of Electronic Business from the Historical Point of View of an ECommerce Concept," Journal Dimensive Management and Public Sector, vol. 2, no. 2, pp. 19-24, 2021, doi: 10.48173/jdmps.v2i2.91

[8] P. Vrbová, V. Cempírek, M. Stopková, and L. Bartuška,” Various Electronic Data Interchange (EDI) Usage Options and Possible Substitution," hrcak, vol. 65, no. 4, 2018, doi: 10.17818/NM/2018/4SI.4

[9] I. Masudin and M. S. Kamara, "Electronic Data Interchange and Demand Forecasting Implications on Supply Chain Management Collaboration: A Customer Service Perspective," Jurnal Teknik Industri, vol. 18, no. 2, pp. 138-148, 2017

[10] M. Kopczewski, Z. Grobelny and M. Plucienniczak," Telematics - electronic data interchange / EDI / in port transport logistics," Journal of Decision Systems, 2021, doi: 10.1080/12460125.2020.1868654

[11] T. O. Nyumba, K. Wilson, C. J. Derrick, and N. Mukherjee, "The use of focus group discussion methodology: Insights from two decades of application in conservation," Methods in Ecology and Evolution, vol. 9, no. 1 pp. 20-32, 2018, doi: 10.1111/2041-210X.12860

[12]H. Rahimi, A. Kalantari, N. Rafiee, and S. Khosravi, "Social Trends Affecting the Future of Iran's Health System: A Qualitative Study Using Focus Group Discussion," International Journal of Preventive Medicine, vol. 10, pp. 15-24, 2018, doi: 10.4103/ijpvm.IJPVM_322_18

[13] J. Sim and J. Waterfield, "Focus group methodology: some ethical challenges," Qual Quant, vol. 53, pp. 3003-3022, 2019, doi: 10.1007/s11135-019-00914-5

[14] R. Yunitarini, P. Pratikto, P. B. Santoso, S. Sugiono, “A Literature Review of Electronic Data Interchange as Electronic Business Communication for Manufacturing”, Management and Production Engineering Review, vol. 9, no. 4, pp. 117-128, 2018, doi: 10.24425/119552

[15] S. Sutiah and S. Supriyono, "Design of Information System for Peace Education Based on Unified Modelling Language," Advances in Social Science, Education and Humanities Research, vol. 529, pp. 248-253, 2021

[16] A. D. Manuputty, S. Hendrawan and B. Haryanto, "Design of Information Systems for Research Permit Application with Agile Method and Website Based Laravel Framework," Journal of Information Systems and Informatics, vol. 2, no. 1, 2020, doi: 10.33557/journalisi.v2i1.45

[17] K. Hamilton and R. Miles, Learning UML 2.0, O’Reilly, UK., 2018

[18]R. Rashkovits and I. Lavy, "Mapping Common Errors in Entity Relationship Diagram Design of Novice Designers," International Journal of Database Management Systems (IJDMS), vol. 13, no. 1, pp. 1-20, 2021

[19] S. Al-Fedaghi, "Conceptual Data Modeling: Entity-Relationship Models as Thinging Machines," IJCSNS International Journal of Computer Science and Network Security, vol. 21, no. 9, pp. 1-14, 2021, doi: 10.22937/IJCSNS.2021.21.9.33

[20]D. Bork, A. Garmendia and M. Wimmer, "Towards a Multi-Objective Modularization Approach for EntityRelationship Models," Judith Michael, Victoria Torres (eds.): ER Forum, Demo and Posters 2020, pp. 45-58, 2020 